\title{
Home parenteral nutrition in chronic intestinal failure
}

\author{
W M Bisset, P Stapleford, S Long, A Chamberlain, B Sokel, P J Milla
}

\begin{abstract}
In children with severe failure of intestinal function, intravenous nutrition is at present the only treatment able to maintain adequate nutrition for prolonged periods of time. Over the last five years we have discharged 10 patients home on parenteral nutrition for a total of 25 patient years and here the outcome of these children is presented. Of the 10 patients, one has discontinued home parenteral nutrition (HPN), seven patients remain well, one patient has recently moved to the USA, and one patient has died after major abdominal surgery. All children had either normal or an accelerated rate of growth on HPN and developmentally all have progressed well. All the children over 5 years attend normal schools. The major complication of treatment was line sepsis with an overall rate of one episode in $\mathbf{4 7 6}$ days and a total of nine central lines (five patients) have required replacement giving an average line life of 680 days. For those children unfortunate enough to suffer from severe intestinal failure, HPN is preferable to prolonged hospital treatment and offers the chance of a good quality of life with prolonged survival.
\end{abstract}

In early childhood inadequate nutrition readily results in stunting of growth and the development of multiple nutritional deficiencies. Where nutritional requirements cannot be met by the enteral route as a consequence of severe gastrointestinal disease and intestinal failure, parenteral nutrition offers a method for maintaining normal growth and development. ${ }^{1-5}$ As a result of developments both in the formulation of parenteral feeding regimens and in the insertion and nursing care of central venous catheters it is now possible for this to be carried out safely for many years. ${ }^{6}$

However prolonged hospital admission has a detrimental effect on the development of young children and is very disruptive to family life. Home parenteral nutrition (HPN) has been available in selected units within the UK for over 10 years in adult patients, ${ }^{7-9}$ but it is only more recently with improvements in parenteral nutrition care that HPN has become available for younger patients. Provisional studies already suggest that the growth and intellectual development of children fed at home parenterally is accelerated after discharge from hospital. ${ }^{10}$

In this paper we describe the selection, organisation, and outcome of 10 children whom we have treated at home with HPN for a total of over 25 patient years and emphasise those aspects peculiar to the UK.

\section{Patients and methods}

PATIENTS

A total of 10 children (five girls, five boys) have been discharged from our unit on HPN over the last five years. Their ages have varied from 10 months to 15 years (mean 4.6 years) and the length of follow up has ranged from 10 months to 4.9 years (mean 2.6 years). This represents over 25 patient years experience of HPN. Two children have been discharged abroad, one to Italy and the other to Malta, and their care is shared. The details of the patients are listed in table 1 .

\section{SELECTION CRITERIA CONSIDERED}

The suitability of a child for HPN is dependent on both medical and social factors. The severity of the child's underlying intestinal disease will determine whether complete or partial HPN is required, whether they have large fluid, electrolyte, and vitamin requirements, and will thus influence the complexity of the child's treatment at home.

While it may be possible for the most able parents to care for a child with complex medical problems on HPN, some parents will be unable to cope with the technical and emotional demands of their child's treatment. Thus the parents need to be highly motivated, have a stable relationship, have adequate housing, and to be of average or greater intelligence.

\section{VENOUS ACCESS}

In all patients Hickman or Broviac Silastic catheters have been aseptically surgically inserted for the intravenous delivery of nutrients. Our preferred site of insertion is in the right or left subclavian vein with the tip of the central venous catheter lying in the right atrium with the catheter tunnelled onto the chest wall. In some children multiple central venous catheter insertions has meant that jugular and femoral veins have also been used. ${ }^{6}$ Single lumen

Table 1 Details of patients who have received HPN

\begin{tabular}{llcl}
\hline $\begin{array}{l}\text { Patient } \\
\text { No }\end{array}$ & Primary disease & $\begin{array}{l}\text { Age at } \\
\text { discharge } \\
\text { (years) }\end{array}$ & $\begin{array}{l}\text { Length of } \\
\text { follow up } \\
\text { (years) }\end{array}$ \\
\hline 1 & Pseudo-obstruction & 3.3 & $4 \cdot 9$ \\
2 & Pseudo-obstruction & 1.7 & $4 \cdot 8$ \\
3 & Pseudo-obstruction & 15.0 & 3.6 \\
4 & Congenital enteropathy & 1.3 & 3.5 \\
5 & Short gut & 1.3 & $2 \cdot 7$ \\
6 & Short gut & 5.5 & 0.8 \\
7 & Congenital enteropathy & 0.8 & 1.8 \\
8 & Short gut & 6.7 & $1 \cdot 7$ \\
9 & Congenital enteropathy & 1.5 & 0.8 \\
10 & Immunodeficiency & $7 \cdot 4$ & 0.8 \\
\hline
\end{tabular}


catheters are used exclusively with their use strictly limited to the delivery of nutrients.

Blockage of a central venous catheter may occur at the tip from the deposition of fibrin or at the hub due to the precipitation of nutrients or salts from the HPN. Urokinase $(5000 \mathrm{U}$ in 3 $\mathrm{ml}$ ) instilled into the catheter for four hours and repeated on successive days up to a maximum of three, will dissolve fibrin, and $70 \%$ alcohol will help dissolve any lipid deposited within the catheter. If the catheter is blocked at the hub, debris may be seen or the lumen may not be visible. Removal of the hub and replacement using a Broviac/Hickman repair kit will restore patency to the catheter. When these methods fail the central venous catheter should be replaced.

\section{NUTRIENTS}

In all cases the nutrients were compounded by Baxter Healthcare (nine in UK, one in Italy). Four of the children who have significant residual intestinal function received an amino acid (Synthamin, Baxter)/dextrose mixture as a single infusion. The remaining six children with very little residual intestinal function received intravenous fat (Intralipid 20\%, KabiVitrum) in addition on two days of the week. In three the Intralipid was formulated in a single bag giving a lipid/amino acid/dextrose mixture, and in three of the older children the lipid was given as a bolus infusion before the infusion of the amino acid/dextrose mixture.

The electrolyte content of the intravenous nutrition was closely matched to the requirements of the child. Trace elements were added to the infusions: copper, zinc, chromium, and manganese (MTE-4, Baxter) along with sodium selenite $0.02 \mu \mathrm{mol} / \mathrm{kg} /$ day (KabiVitrum). In those patients with some residual absorptive function, fat and water soluble vitamins were given as Ketovite tablets and liquid (Paines and Byrne): six tablets and $10 \mathrm{ml}$ per day (double the normal dose). In two children with very little gut absorptive function, vitamins were given intravenously as Solvito (KabiVitrum) and Vitalipid (KabiVitrum). The shelf life of non-lipid containing nutrient bags is three months and for those containing lipid it is only one month.

The intravenous feeds were given at night over 12 hours and in those children who were not on total HPN this was supplemented by oral feeds during the day. When possible the HPN was given over five or six nights per week to allow the parents a night free.

\section{SUPPLY OF NUTRIENTS}

For the patients living in the UK we have exclusively used the services of a commercial homecare company (Unicare Medical Services Ltd, Harlow, Essex) to supply and deliver nutrients and disposables to the child's home. The Maltese child received his HPN by air freight from the UK and the nutrients for the Italian child were manufactured locally. The intravenous nutrient solutions were delivered at intervals of two weeks to the child's home along with the ancillary supplies. Space must be available in the family home to store intravenous feeding solutions, consumables, and the items of equipment listed in table 2 .

\section{FUNDING}

The intravenous nutrient solutions were prescribed by the child's general practitioner on a FP10 form and the cost was therefore borne by the family practitioner budget. The services of the homecare company and the recurring cost for the provision of ancillary supplies have been met from the budget of the health authority in which the child lives.

\section{TRAINING AND COMMUNITY SUPPORT}

Before discharge both parents were instructed by our nutrition nurse in the care of the feeding catheter and the safe delivery of the nutrients. Training takes two to three weeks during which time both parents are resident in the hospital. Nursing staff from the referring hospital and carers from nursery or primary school were also instructed in the emergency care of the central line. The specific points taught to the parents are listed in table 3. A home visit was made by our nutrition nurse to assess the suitability of the child's home for HPN. The child should

\section{Table 2 Equipment needed for a child on HPN}

Intravenous infusion pump (leasing availability from homecare company with 4 hour backup service)

Pump stand

Dressing trolley (folding)

Refrigerator (for storage of HPN bags)

Intravenous giving sets

Sterile clamps
Dressing packs

Chlorhexidine

Syringes and needles

Saline and heparinised saline flush

Sharps' bins and bin bags (with clinical waste disposal service)

Catheter caps

Storage shelves (giving sets, dressing packs, etc)

Storage shelves (giving sets,
Mepore dressings (Mölnlycke)

Mepore dressin

Treatment area (usually in bedroom)

13 amp plug points

Telephone

Adequate plumbing facilities

Table 3 Points taught to both parents before child discharged home on HPN

Hand washing technique

Principles of asepsis:

Preparation of sterile field

Putting on sterile gloves

Drawing up solutions into syringe

Catheter care:

Heparinisation and flushing catheter

Exit site care

Infusion:

Priming of giving sets

Initiation/termination of infusion

Care of parenteral nutrients

Care of infusion pump:

Pump operatio

Maintenan

Alarms

Monitoring at home:

Urinalysis

Temperature taking if feverish

Problem solving:

Temperatures

Accidental disconnection of line

Blockage of line

Air in line

Breakage/split catheter

Who to contact in an emergency (24 hours) 
ideally have a bedroom to themselves with adequate space in the house for the storage of the ancillary items and nutrient solutions. A professional's meeting was arranged so that the general practitioner, health visitor, social services, and other community health care professionals were fully involved and were aware of the needs of the child and family once he or she was home. With four patients minor alterations were required to the family home to accommodate the HPN. All families in the UK have successfully applied for an attendance allowance.

\section{MONITORING OF HPN}

A summary of the monitoring regime used is shown in table 4 . Where possible monitoring was shared with the local referring hospital.

\section{DEVELOPMENT}

We assessed the developmental progress of the children at the time of discharge and at home by serial assessment. All tests were carried out by the same clinical psychologist using tests appropriate for their age. The Griffiths's mental development scale was used in those under 3.8 years, ${ }^{11} 12$ the Wechsler preschool and primary scale of Intelligence (WPPSI) for those under 6.5 years, ${ }^{13}$ and the Wechsler intelligence scale for children revised (WISC-R) in the older children. ${ }^{14}$ The Griffiths's score is presented as a general quotient (GQ) and the other scores as an intelligence quotient (IQ).

\section{STATISTICS}

A paired $t$ test was used to compare height SD scores and the $95 \%$ confidence intervals (CI) are quoted.

\section{Results}

Of the 10 children who were discharged on home parenteral nutrition, eight are presently alive and well, one has moved to the USA after $2 \cdot 7$ years of follow up (patient 5), and one patient has died from the surgical complications of her underlying short gut syndrome (patient 6). Since discharge from hospital the patients have progress well with few complications, particularly over the last nine patient years when there have been no infective or nutritional complications in any of our patients. Of the eight well patients, seven remain on HPN while one child has been able to discontinue intravenous nutrition after 3.5 years of HPN (patient 4).

\section{GROWTH AND NUTRITION}

Before starting HPN all of the patient weights were within the normal range for age and all but one of the heights were within 2 SD of the mean for their age. One child who was chronically malnourished for many years before starting intravenous feeding (patient 8) had a height which was 5.13 SD below the mean. After the start of HPN all of the children have maintained their weight within the normal range and there has been a significant increase (mean of differences $0.837,95 \%$ CI 1.53 to 0.143 ) in their SD score for height. This effect is most noticeable in the stunted patient where the growth velocity increased from $4.0 \mathrm{~cm} /$ year before starting HPN to $10.4 \mathrm{~cm} /$ year after. The growth results are summarised in fig 1 .

Nutritional deficiencies occurred in the first patients discharged (patient 1-5) on HPN, but now with the improved formulation of feeding regimens and better monitoring we have experienced no nutritional complications in our patients over the last 15 patient years. Patient 1 was discharged on oral vitamin supplements but unfortunately these were not taken by the child, leading to the development of Wernicke's encephalopathy and in another with short gut syndrome (patient 5) deterioration in stool

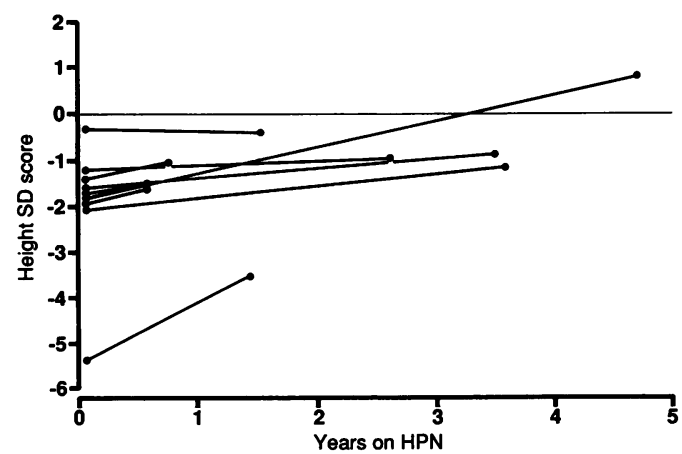

Figure 1 The change in height as measured by the SD score, over the period of HPN. Height unavailable for patient discharged to Italy.

Table 4 Investigations for the monitoring of HPN

\begin{tabular}{lll}
\hline Time & Investigation \\
\hline Before discharge & All investigations shown below \\
4-6 Weeks & $\begin{array}{l}\text { Anthropometry } \\
\text { Haematology } \\
\text { Biochemistry }\end{array}$ & $\begin{array}{l}\text { Weight, height } \\
\text { Full blood count } \\
\text { Urea and electrolytes, calcium, magnesium, liver } \\
\text { function tests, urine electrolytes } \\
\text { Urine culture, line site }\end{array}$ \\
3 Months & $\begin{array}{l}\text { Hacteriology (if indicated) } \\
\text { Biochemistry }\end{array}$ & $\begin{array}{l}\text { Ferritin, clotting } \\
\text { Copper, zinc, selenium }\end{array}$ \\
Hanths & $\begin{array}{l}\text { Haematology } \\
\text { Biochemistry } \\
\text { If indicated } \\
\text { Radiology }\end{array}$ & $\begin{array}{l}\text { Folate, vitamin B-12 } \\
\text { Vitamin B-1, B-2, B-6, vitamin A, E, D } \\
\text { Aluminium, chromium, manganese, essential fatty acids } \\
\text { Liver ultrasound, chest radiography }\end{array}$ \\
$\begin{array}{l}\text { Cardiology } \\
\text { Psychology }\end{array}$ & $\begin{array}{l}\text { Echocardiography } \\
\text { Developmental assessment }\end{array}$ \\
\hline
\end{tabular}


losses resulted in zinc deficiency despite intravenous supplementation. The first five patients discharged developed subclinical selenium deficiency because their HPN did not contain any supplements. ${ }^{15}$ In all cases the deficiencies were corrected with no long term sequelae for the children.

\section{BIOCHEMISTRY}

Despite the fact that some of the children had large stool losses of fluid and electrolyte it was possible in all cases to maintain a good balance. In one child (patient 6) who lost 1 litre of fluid and $150 \mathrm{mmol}$ of sodium per day from a high jejunostomy, this was compensated for by appropriate additions to the intravenous feed.

It is well recognised that liver disease is frequently associated with long term intravenous feeding. In three patients (patients $6,7,10$ ) the activity of aspartate aminotransferase was chronically raised above $100 \mathrm{IU} / 1$ (normal range $<40 \mathrm{IU} / \mathrm{l}$ ) and in the remaining patients the activity was maintained either within or just above the normal range. Only one of these three patients (patient 7) has undergone serial liver biopsy, which has shown evidence of mild nonprogressive periportal fibrosis. No patients have had raised bilirubin concentrations at home, although the patient who died after abdominal surgery developed a cholecyst-enteral fistula, ascending cholangitis, and jaundice as a preterminal event. One infant has developed gall stones (patient 7) and has undergone a cholecystectomy. A second child (patient 9) had evidence of 'sludge' in the gall bladder that has subsequently resolved after increased enteral food tolerance. ${ }^{1617}$

VENOUS ACCESS, LINE CARE, AND INFECTION Venous access is always a limiting factor in the delivery of intravenous feeding and great care is required to extend the life of feeding catheters. Due to the care and dedication of the parents the average line life is $\mathbf{6 8 0}$ days with a range of eight to 1760 days.

The incidence of line sepsis is difficult to calculate as some septicaemic episodes may originate from the intestine. In six of the 10 children (patients $2,3,7,8,9,10$ ) no septicaemic episodes have occurred since discharge home, while a total of 19 episodes have occurred in the remaining four children (patients $1,4,5,6$ : one pseudo-obstruction, two short gut, one congenital enteropathy). In 13 of these episodes an enteric organism was isolated from blood culture and Staphylococcus epidermidis and a streptococcus were responsible for the remaining case. The overall rate of septicaemia was one in 476 days.

Line infections were treated with intravenous antibiotics delivered through the line for 10 days. Where the patient became very unwell and/or the infection was not brought under control within 72 hours or recurred after the cessation of antibiotics the feeding catheter was removed and electively replaced three to seven days later. Redness at the entry site of the catheter to the skin tunnel occurred in most of the patients and settled, in all but one case (patient 4), with the topical skin application of chlorhexidine. In the latter case the line was removed. ${ }^{1819}$

A total of nine lines have been replaced in five of the patients (patients $1,3,4,5,6$ ). Five were removed because of catheter related sepsis, in one the line was damaged beyond repair, in another poor scar formation around the catheter cuff led to the line falling out, in one patient an innominate vein thrombosis precipitated catheter removal, and in one patient a catheter could not be unblocked. ${ }^{20}{ }^{21}$ In two patients with a blockage of the catheter hub, replacement of the hub using a Broviac repair kit allowed us to save the feeding catheter without resorting to replacement of the central line.

\section{DEVELOPMENT}

All of the children were within the normal range at the time of discharge, and while on HPN their development has progressed normally (fig 2). Specific delay in the development of speech was noted in four of the younger children and in three this corrected after discharge home. In the fourth patient (patient 4) speech therapy and treatment for middle ear disease has been required.

\section{EDUCATION}

All seven children of school age attend normal school. One child with an ileostomy (patient 1) goes to a normal school where extra help is available. Another child with speech problems (patient 4) as a consequence of a palatal defect and middle ear disease attends a normal school with a special language unit. A third child (patient 8) who missed prolonged periods of schooling before starting HPN requires some remedial teaching. Physical contact and games with other children were not restricted and some of the children go swimming with their central venous catheter protected by a clear waterproof film (for example, Tegaderm, $3 \mathrm{M}$ Healthcare). ${ }^{22} 23$ The oldest child has recently sat his university entrance examinations.

\section{FAMILY HOLIDAYS}

All the families have been able to take a holiday with their child. This has inevitably meant taking the infusion pump and intravenous

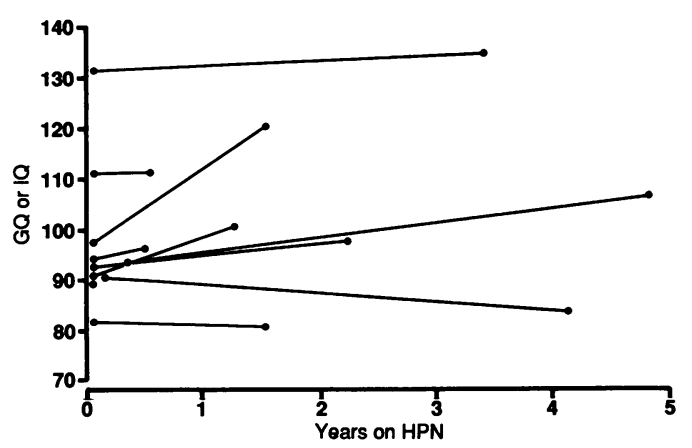

Figure 2 The development progress of the children while on $H P N$ as expressed by their $G Q$ or IQ. Developmental tests described in text. Incomplete data for patient who died. 
nutrients with them and as a consequence most have gone by car and have stayed in self catering accommodation. We have, however, been able to arrange holidays in the USA and Sicily as the company that manufactures the HPN has subsidiaries throughout the world.

\section{ORGANISATION}

With seven of the eight British children their original general practitioners' (GP) agreed to prescribe the HPN. In one case a single handed GP was not prepared to take responsibility for the child at home and a new GP was found. The cost of the HPN solutions was $£ 20000-£ 25000$ per year but due to special dispensation from the Department of Health the GPs were not penalised. Difficulties in contacting the budget holder for community services has led to problems in arranging HPN. Because the referral hospital and the patient's home may be in different health authorities there was often considerable delay between a request being made and an agreement reached. On average it has taken three months to arrange for the discharge of a child on HPN, although this has ranged from between one month to discharge a child back to Italy to over 18 months to discharge a child home to a south London health district which has no community resources. We have found that most health authorities have no provision in their budgets for the care of children requiring long term medical treatment at home and as a consequence it may take some time for them to find the required funding. The community funding of the infusion pump and consumables cost $£ 3000-£ 5000$ per year.

\section{Discussion}

Our experience over the last five years would suggest that HPN is a safe and efficient means of delivering nutrients to children with chronic intestinal failure. The children are able to grow and develop normally at home with their families and apart from their gut disease they are essentially healthy normal children.

Many consider parenteral nutrition as highly dangerous and regard it as a treatment of last resort. This view stems from the time when nutrients were compounded by ward staff, venous access was poor, and as a result of poor sterile technique morbidity and mortality from sepsis were unacceptably high. The advances in knowledge regarding parenteral nutrition and its nursing care means that this is no longer the case and intravenous feeding should be considered at an early stage for the treatment of severe gastrointestinal disease. Although it is generally assumed that the medical care of a child requiring intravenous nutrition would be best carried out by trained staff in hospital, our study and a number of others show quite clearly that this is not the case and that well trained and supported parents are more than capable of performing this task at home. ${ }^{1245}$ Appreciably reduced line sepsis rates and prolonged line survival in home patients almost certainly relate to the consistent care the children receive from highly motivated parents and parallels similar findings in adult patients at home. ${ }^{19}$ It is noteworthy that in two of our patients line infections occurred not at home but during brief hospital admissions for respite care.

Our data suggest that simple HPN regimens, which do not require the addition of intravenous supplements such as vitamins or trace metals at home, are likely to carry the lowest sepsis rates. This is illustrated by patient 1 who had six episodes of line sepsis in the first three years of HPN, at a time when trace elements were being added by her mother to the HPN, and no further episodes in the subsequent two years after these additions were made aseptically at the time of bag manufacture.

There was no relationship between the type of infective organism, the underlying intestinal disease, and the central venous catheter insertion site. The appreciable reduction in the incidence of septicaemia in HPN due to both Gram positive and Gram negative organisms, in patients in whom there had been no change in their underlying disease, strongly suggests that these infections were acquired from exogenous sources. This therefore casts doubt on the commonly held belief that septicaemia with an enteric organism, in a patient with a central venous catheter, must be due to endogenous spread from an intra-abdominal source.

With the improved life of central venous catheters it is likely that good venous access can be maintained in these children into adult life.

Hospital provides the young child with a very artificial environment, a lack of time for play, inconsistencies in handling, and infrequent mixing with children of a similar age and can result in the development of mild global development delay. Although with appropriate intervention it is possible to reduce this to a minimum, it is probably only once the child is returned to their home that they are able to meet their full potential. ${ }^{10}$ Our study confirms this with normal somatic growth paralleled by normal neurological and intellectual development occurring after discharge from hospital.

All nutritional deficiencies occurred in the first five patients discharged home, and through a better understanding of the nutritional needs of these children we have not diagnosed any major deficiencies in the last three years. ${ }^{24-26}$ However most routine biochemistry laboratories are unable to monitor all trace metals, water soluble vitamins, or essential fatty acids and as a consequence the need to send specimens to special reference laboratories is an added administrative and financial burden.

The parents are aware that the survival of their child is dependent on their skill in delivering the HPN and many find this a great burden. Some parents also feel trapped by the needs of the child but find that when they seek help from support agencies there is no understanding of the medical problems of the child or the social or emotional needs of the parents. Despite these problems all the parents feel that caring for their child at home is very rewarding and infinitely preferable to the child remaining in hospital. However the group of patients we describe here is highly selected and where a 
child has multiple organ failure or the family or medical services are unable to implement intravenous feeding at home, long periods in hospital may be unavoidable.

The greatest difficulty and cause of delay in arranging HPN is in agreeing the financial arrangements. In the USA the move toward the early institution of HPN in children with chronic intestinal failure has been driven largely by financial considerations and by the realisation that children requiring parenteral nutrition progress better at home from a nutritional and psychological viewpoint than those children who remain in hospital. This is further facilitated by the many commercial homecare companies who are able to manufacture the parenteral feeds and help train and support the parents at home. As the cost of health care in the USA is largely financed through medical insurance there are real incentives for the treatment of chronic problems at home rather than in hospital.

In the UK it costs approximately $£ 100000$ each year to keep a child in hospital to receive intravenous nutrition against a cost of $£ 20000$ $£ 30000$ to receive the same treatment at home. Unfortunately, as a result of the budgetary arrangements within the National Health Service, the small number of homecare companies, and the poor level of development of community services, the incentives to send these children home do not exist and as a consequence the arrangement of HPN is difficult. The lack of any proper central funding for HPN in either children or adults means that the financial burden of funding this form of treatment must be borne by the family practitioner budget and the community budget of the local health authority. Unfortunately this is often seen as an added burden rather than as a large overall financial saving to the health service.

Because of these delays and difficulties children with conditions such as the short gut syndrome who might benefit from a short period (three to six months) of HPN while their intestine is adapting, require to remain in hospital at great expense to the health service. If arrangements for HPN could be made more swiftly, many of these patients would benefit from an early hospital discharge.

We have relied very heavily on the services of a commercial homecare company to arrange for the formulation and delivery of the HPN to our patients. Where a unit is caring for children on HPN who are all living close to their hospital there may be attraction in providing the whole service from local resources. We find that with patients scattered all over southern England, the homecare company is able to maintain consistent stock levels of supplies, take care of much of the administration, and continues to provide a service when the patient moves house or goes on holiday and have even arranged for the manufacture of HPN bags in other countries when the children go abroad on holiday.

For children with severe gastrointestinal disease unfortunate enough to be dependent on intravenous nutrition, HPN offers the prospect of a good quality of life with prolonged survival.
Many children are likely to benefit from this treatment but until community services become better developed and funding arrangements within the health service more flexible it is likely that many children will continue to languish in hospital. Our study shows that this treatment is not only cheaper to the health service but offers the child the prospect of reduced morbidity with normal growth and development and a quality of life which allows them to fulfil their true potential.

1 Gorski AM, Goulet O, Lamor M, et al. Nutrition parenterale a domicile chez l'enfant. Bilan de 8 ans d'activite chez 88 malades. Arch Fr Pediatr 1989;46:323-9.

2 Amarnath RP, Fleming CR, Perrault J. Home parenteral nutrition in chronic intestinal diseases: its effect on growth and development. F Pediatr Gastroenterol Nutr 1987;6: and deve.

3 Dahlstrom KA, Strandvik B, Kopple J, Ament ME. Nutritional status in children receiving home parenteral nutrition. tional status in children receivin

4 Pitt HA, Mann LL, Berquist WE, Ament ME, Fonkalsrud EW, DenBesten L. Chronic intestinal pseudo-obstruction. Management with total parenteral nutrition and a venting enterostomy. Arch Surg 1985;120:614-8.

5 Cannon RA, Byrne MJ, Ament ME, Gates B. Home parenteral nutrition in infants. F Pediatr 1980;96:1098-104.

6 Pokorny WJ, Black CT, McGill CW, Splaingard ML, Harrison GM, Harberg FJ. Central venous catheters in older children. Am Surg 1987;53:524-7.

7 Stokes MA, Irving MH. Mortality in patients on home parenteral nutrition. Fournal of Parenteral and Enteral Nutrition 1989;13:172-5.

8 Ward MWN, Harrison RA, Doyle J, Clark CG. Parenteral nutrition at home. Practitioner 1984;228:831-3.

9 Griffith CDM, Quale AR, Clark RG, Gurnell P. Home parenteral nutrition in Sheffield 1978-1983. F Coll Surg Edinb 1984;29:335-8.

10 Ralston CW, O'Connor MJ, Ameny M, Berquist W, Parmalee AH. Somatic growth and developmental functioning in children receiving prolonged home total parenteral nutrition. f Pediatr 1984;105:842-6.

11 Griffiths R. The abilities of babies; a study in mental measurement. Amersham: Association for Research in Infant and Child Development, 1954

12 Griffiths R. The abilities of young children; a comprehensive system of mental measurement for the first 8 years of life. London: Clinical Development Research Centre, 1970.

13 Wechsler D. Manual of the Wechsler pre-school and primary scale of intelligence. New York: Psychological Corporation, 1967.

14 Wechsler D. Manual for the Wechsler intelligence scale for children-revised. New York: Psychological Corporation. 1974

15 Kien CL, Ganther HE. Manifestations of chronic selenium deficiency in a child receiving total parenteral nutrition. $\mathrm{Am}$ deficiency in a child receiving
7 Clin Nutr 1983;37:319-28.

16 Cohen C, Olsen MM. Pediatric total parenteral nutrition. Liver histopathology. Arch Pathol Lab Med 1981;105: $152-6$

17 Roslyn JL, Berquist WE, Pitt HA, et al. Increased risk of gallstones in children receiving total parenteral nutrition. Pediatrics 1983;71:784-9.

18 Ladefoged K, Efsen F, Christoffersen JK, Jarnum S. Longterm parenteral nutrition. II. Catheter-related complications. Scand $\mathcal{F}$ Gastroenterol 1981;16:913-9.

9 Rannem T, Ladefoged K, Tvede M, Lorentzen JE, Jarnum S. Catheter-related septicaemia in patients receiving home parenteral nutrition. Scand 7 Gastroenterol 1986;21:455-60.

20 Franciosi RA, Ellefson RD, Uden U, Drake RM. Sudden unexpected death during central hyperalimentation. Pediatrics 1982;69:305-7.

21 Graham L, Gumbiner $\mathrm{CH}$. Right atrial thrombosis and superior vena cava syndrome in a child. Pediatrics 1984;73: 225-9.

22 Berry RK, Jorgensen S. Growing with home parenteral nutrition: adjusting to family life and child development.

23 Berry RK, Jorgensen S. Growing with home parenteral nutrition: maintaining a safe environment. Pediatric Nursing 1988;14:155-7.

24 Bowyer BA, Fleming CR, Ilstrup D, Nelson J, Reek S, Burnes J. Plasma carnitine levels in patients receiving home Burnes J. Plasma carnitine levels in patients receiving h

parenteral nutrition. Am f Clin Nutr 1986;43:85-91.
25 Klein GL, Horst RL, Alfrey AC, Slatopolsky E. Serum levels of 1,25 -dihydroxy vitamin $\mathrm{D}$ in children receiving parof 1,25-dihydroxy vitamin $\mathrm{D}$ in children receiving parenteral nutrition with reduced alum

26 Geggel HS, Ament ME, Heckenlively JR, Martin DA, Kopple JD. Nutritional requirements for taurine in patients receiving long-term parenteral nutrition. $N$ Engl $\mathcal{J}$ Med 1985;312:142-6. 